\title{
Reduction of oxidative stress does not affect recovery of myocardial function: warm continuous versus cold intermittent blood cardioplegia
}

Bonizella Biagioli, Emma Borrelli, Massimo Maccherini, Giorgio Bellomo, Gianfranco Lisi, Pierpaolo Giomarelli, Guido Sani, Michele Toscano

Abstract

Objective-To compare oxidative stress after cardiac surgery in patients treated with two different methods of myocardial protection: warm continuous versus cold intermittent blood cardioplegia. To correlate oxidative stress with postoperative myocardial dysfunction.

Design-Prospective, randomised, double blind, trial.

Setting-Institutional centre of cardiovascular surgery.

Patients-20 patients were selected for coronary artery bypass surgery (CABG) on the following basis: stable angina, ejection fraction $>50 \%$, double or triple vessel disease, no previous CABG or associated disease. Patients were randomised to two groups of 10 patients each.

Interventions-Patients

underwent CABG with one of two different methods of myocardial protection and cardiopulmonary bypass. CBC group: intermittent cold blood antegrade-retrograde cardioplegia with moderate hypothermic cardiopulmonary bypass; WBC group: continuous warm blood antegraderetrograde cardioplegia with mild hypothermic cardiopulmonary bypass. Main outcome measure-The index of oxidative stress used was the alteration of whole blood and plasma glutathione redox status. Samples were collected from the coronary sinus and peripheral vein before anaesthesia (T1), before aortic unclamping (T2), 15 minutes (T3), and 30 minutes (T4) after unclamping. Haemodynamic parameters were measured with thermodilution techniques.

Results-Oxidised glutathione and glutathione-cysteine mixed disulphide significantly increased in the coronary sinus plasma in the CBC group, and the overall redox balance of glutathione was decreased $(P<0.01)$ at $T 2-T 4$ versus $T 1$, and compared with the WBC group. Comparable results were obtained for coronary sinus blood. There was no correlation between postoperative haemodynamic measurements and oxidative stress markers.

Conclusions-Oxidative stress was significant in patients undergoing CABG using cold blood cardioplegia, while the warm technique minimised the effects of ischaemia. However, oxidative stress was not correlated with myocardial dysfunction following CABG.
(Heart 1997;77:465-473)

Keywords: oxygen free radicals; blood cardioplegia; coronary artery bypass graft

Knowledge of myocardial stunning as a primary consequence of reperfusion in humans remains elusive, compared with numerous in vitro perfused organ preparations and in vivo animal studies. Despite improvements in surgical and myocardial protection techniques, postoperative ventricular dysfunction after cardiac surgery is common clinically ${ }^{1-3}$ and observed experimentally, ${ }^{4-6}$ and may represent "global stunning". In many cases there was no evidence of myocardial necrosis following total ischaemia by aortic clamping and reperfusion of the ventricle. ${ }^{7}$ Evidence of a role for oxygen derived free radicals is overwhelming in most experimental preparations: the generation of free radicals has been demonstrated and measured directly in myocardial tissue after a transient period of ischemia-reperfusion by spin trapping and electron paramagnetic resonance (EPR) techniques ${ }^{8-10}$; there is a relation between the activity of free radicals and the entity of stunning; antioxidant and free radical scavengers enhance recovery of function in stunned myocardium. ${ }^{11-13}$ Confirmation of these findings in the postischaemic human myocardium has been elusive, as we must rely on indirect criteria to assess oxidative stress and the effects of anti-free radical interventions in the clinical setting. ${ }^{14-16}$ To date there is a limited number of reports suggesting the presence of oxidative stress following reperfusion of the postischaemic human heart. ${ }^{17-19}$ None of the studies prove that the magnitude of free radical formation found is harmful, although they do support the overall concept that free radicals are formed during reperfusion and may contribute to reperfusion injury. ${ }^{20} 21$ Nonetheless, Ferrari et al have reported the occurrence of major changes of glutathione content and redox balance in coronary sinus plasma during postischaemic reperfusion in patients subjected to crystalloid cardioplegia for coronary artery bypass grafting (CABG). ${ }^{17}$ They found a positive correlation between the duration of ischaemia and the release of oxidised glutathione; in addition, the recovery of the cardiac index was inversely related to the measurements of oxidative stress. Furthermore, Bolli et al have clarified that the degree of postischaemic dysfunction is primarily determined by the severity and duration of previous ischaemia. ${ }^{8}$ Using EPR, they 
showed a linear relation between the magnitude of free radical generation and ischaemic flow reduction. These findings imply that, regardless of the precise mechanism responsible for stunning, the mechanism must be initiated and regulated by ischaemia, and any intervention that improves perfusion during ischaemia would be expected to attenuate stunning after reperfusion.

These findings prompted our investigation of a new method of myocardial protection developed by Lichtenstein et al. ${ }^{22}$ The basic concept of this method is the association of chemical electromechanical arrest (by potassium) with a continuous warm blood (WBC) perfusion to prevent myocardial ischaemia. In the past few years, methods have been developed to modify cardioplegia and reperfusion constituents, or to supply various antioxidants with the aim of reducing reperfusion injury after cardioplegic arrest during cardiac surgery. ${ }^{23}$ The goal of WBC is not only to provide substrate, oxygen, and perfusion to achieve some degree of cellular repair but also to prevent additional damage from ischaemia, hypothermia, reperfusion, and oxidative stress.

In the present study, the alterations of glutathione redox status (taken as an indirect index of oxidative stress) occurring in plasma and whole blood were measured into two groups of 10 patients undergoing different techniques of myocardial protection for CABG. Furthermore, the presence of a correlation between oxidative stress and myocardial function in the early postoperative hours was investigated.

\section{Patients and methods PATIENTS}

From January to July 1993, 20 patients scheduled for elective CABG were selected on the basis of symptoms and cardiac catheterisation-stable chronic angina, double or triple coronary artery vessels disease $(>50 \%$ reduction in luminal diameter), and preserved left ventricular function (ejection fraction $>50 \%$, left ventricular end diastolic pressure $<15$ $\mathrm{mm} \mathrm{Hg}$, no dyskinetic alteration of left ventricular wall motion). To obtain homogeneous groups we excluded patients with recent myocardial infarction (within one year), previous CABG, combined surgical procedures, pharmacologically treated diabetes, severe hypertension (systolic blood pressure $>180 \mathrm{~mm} \mathrm{Hg}$, diastolic blood pressure $>120 \mathrm{~mm} \mathrm{Hg}$ ), and associated diseases.

The surgical staff was the same for all the patients. The extent of coronary artery disease and general patient characteristics are shown in table 1 . The 20 patients were randomised into two groups. Each patient scheduled for surgery was assigned a progressive number; patients with odd numbers were randomised to the WBC technique, and patients with even numbers to intermittent cold blood cardioplegia $(\mathrm{CBC})$. All patients gave informed consent to participate in this study, which had the approval of the local medical ethics committee. Patients treated with allopurinol or other antioxidant agents were excluded from the present study.

\section{SURGICAL TECHNIQUE}

Antianginal medications (nitrates and calcium channel blockers) were continued until the morning of operation. Anaesthesia was induced with fentanyl $(5 \mathrm{mg} / \mathrm{kg})$ combined with diazepam $(0.3 \mathrm{mg} / \mathrm{kg})$ and maintained with fentanyl infusion $(25 \mu \mathrm{g} / \mathrm{kg} / \mathrm{min})$. Muscle relaxation was achieved with pancuronium bromide $(0.1 \mathrm{mg} / \mathrm{kg})$. Ventilation with a mixture of oxygen and nitrous oxide (50:50) was adjusted to maintain normocapnia. In the CBC group, during bypass haematocrit was maintained between $20 \%$ and $25 \%$ and pump flows were maintained between 2.0 and $2 \cdot 21 / \mathrm{min} / \mathrm{m}^{2}$. In the WBC group, to supply the increased metabolic requirements, flow rates were between 2.2 and $2.51 / \mathrm{min} / \mathrm{m}^{2}$ and haematocrit between $22 \%$ and $25 \%$. In both groups, mean arterial pressure was maintained between 60 and $70 \mathrm{~mm} \mathrm{Hg}$ using sodium nitroprusside $(0.5-5 \mu \mathrm{g} / \mathrm{kg} / \mathrm{min})$ or noradrenaline $(0.01-0.5 \mu \mathrm{g} / \mathrm{kg} / \mathrm{min})$.

In both groups coronary sinus was cannulated blindly with a Research Medical Inc retroplegic cannula (Salt Lake City, Utah, USA); venous drainage was by a two stage cannula and internal mammary artery bypasses were implanted as the last anastomoses.

\section{CARDIOPLEGIC TECHNIQUES \\ $C B C$ group}

Cold blood cardioplegia was administered at a 4:1 ratio of oxygenated circuit blood and crystalloid solution. The physical and biochemical composition of the blood cardioplegic solution were in accordance with the protocol suggested by the UCLA Medical Centre ${ }^{24}$ except that our solution did not contain aspartate and glutamate. The delivery was sequentially divided between antegrade and retrograde through the aorta and through the coronary sinus; arrest was achieved with an initial cold $\left(4-8^{\circ} \mathrm{C}\right)$ blood "high potassium" solution $(20-25 \mathrm{mEq} / \mathrm{l})$ with a flow rate of 200 $300 \mathrm{ml} / \mathrm{min}$ for two minutes through the aorta and then for two minutes through the coronary sinus where the perfusion pressure was maintained below $40 \mathrm{~mm} \mathrm{Hg}$. On completion of each distal-proximal anastomoses or at 20 minute intervals, potassium solution (8$10 \mathrm{mEq} / \mathrm{l}$ ) was administered at a flow rate of $150-200 \mathrm{ml} / \mathrm{min}$ for one minute through the aorta and then for one minute through the coronary sinus. Before cross clamp release, warm $\left(37^{\circ} \mathrm{C}\right)$ blood "low potassium" solution was infused at a flow rate of $150 \mathrm{ml} / \mathrm{min}$, alternating between the aortic root and the coronary sinus at a pressure of $50 \mathrm{~mm} \mathrm{Hg}$ for three to five minutes. ${ }^{23}{ }^{24}$ In this group moderate systemic hypothermia $\left(28-30^{\circ} \mathrm{C}\right)$ and topical hypothermia were used.

\section{WBC group}

Warm blood perfusion was administered through the combined antegrade (aorta) and retrograde (coronary sinus) route. Oxygenated blood was taken from the arterial line of the 
Table 1 Clinical information

\begin{tabular}{lll}
\hline & $\begin{array}{l}C B C \text { group } \\
(n=10)\end{array}$ & $\begin{array}{l}\text { WBC group } \\
(n=10)\end{array}$ \\
\hline Age (years) & $60 \cdot 7(10 \cdot 1)$ & $62 \cdot 3(11 \cdot 1)$ \\
Sex (male/female) & $9 / 1$ & $9 / 1$ \\
CCS class (preop) & $2 \cdot 75(0 \cdot 4)$ & $2 \cdot 9(0 \cdot 6)$ \\
Diseased vessels (No/patient) & $2 \cdot 4(0 \cdot 8)$ & $2 \cdot 6(0 \cdot 5)$ \\
LV class (AHA) & $1 \cdot 3(0 \cdot 4)$ & $1 \cdot 6(0 \cdot 5)$ \\
MI (preop) & 6 & 7 \\
Grafts (No/patient) & $2 \cdot 75(0 \cdot 9)$ & $3(0 \cdot 8)$ \\
CPB time (min) & $123(36)$ & $109(43)$ \\
Cross clamp time (min) & $93(33)$ & $90(23)$ \\
CK max (U/l) & $1126(695)$ & $1850(1357)$ \\
CK-MB max (U/L) & $68(23)$ & $65(19)$ \\
\hline
\end{tabular}

Values and mean (SD). P not significant for all variable by student Newman-Kewls $t$ test.

CCS class, Canadian Cardiovascular Society angina class; LV class (AHA), left ventricular class CCS class, Canadian Cardiovascular Society angina class; LV class (AHA), left ventricular class
(American Heart Association); MI, myocardial infarction; CBP, cardiopulmonary bypass; CK,
creatine kinase. and coronary sinus pressure $<40 \mathrm{~mm} \mathrm{Hg}$. Potassium infusion was regulated according to the Fabri formula ${ }^{25}$ to obtain a $\mathrm{K}^{+}$serum concentration of about $5.5 \mathrm{mEq} / \mathrm{l}$. In this group systemic mild hypothermia $\left(34-35^{\circ} \mathrm{C}\right)$ was obtained by allowing for a drift of core temperature at room temperature. The use of "blower" devices was requested to optimise the visualisation of the anastomoses procedures.

DATA ACQUISITION AND BIOCHEMICAL ASSAY Sampling of plasma and whole blood for measurements of reduced glutathione (GSH), oxidised glutathione (GSSG), and glutathione-cysteine mixed disulphide (Cys-SG) was done in the operating theatre; samples included coronary venous blood from the retrograde cannula, and peripheral blood from venous return of the cardiopulmonary circuit. Blood samples for control measurements were obtained from peripheral veins of healthy subjects. The measurements were made by high performance liquid chromatography (HPLC) according to Reed et al. ${ }^{26}$ Each blood sample was divided in two $100 \mu \mathrm{l}$ aliquots: one was immediately dropped in $0.9 \mathrm{ml}$ of $0.6 \%$ perchloric acid, mixed, and stored at $-80^{\circ} \mathrm{C}$; the other was centrifuged, the plasma fraction
Figure 1 Modifications of the glutathione redox status in the coronary sinus plasma during cardioplegic arrest and reperfusion. Data are reported as median, 25th, and 75th centile. T1, Before cardioplegia and the start of cardiopulmonary bypass; $T 2$, one minute before aortic unclamping; T3, 15 minutes after aortic unclamping and reperfusion; T4, 30 minutes after aortic unclamping reperfusion. $G S H$, reduced glutathione; GSSG, oxidised glutathione; Cys-SG, glutathione-cysteine mixed disulphide; Ratio GSH/(GSSG + Cys-SG). $C B C$ group, intermittent blood cardioplegia and warm modified reperfusion; WBC group, continuous warm blood cardioplegia. ${ }^{\star} C B C$ values significantly different from control $(P<0.05) ;+C B C$ values significantly different from T1 $(P<0.05)$; $\ddagger C B C$ values significantly different from WBC $(P<0.03)$; $₫ C B C$ values significantly different from WBC $(P<0.01)$. bypass circuit and delivered with a roller pump, potassium was added with a syringe pump ( $16 \mathrm{mEq}$ of $\mathrm{K}^{+}$and $3 \mathrm{mEq}$ of $\mathrm{Mg}^{++}$per $20 \mathrm{ml}$ ) directly into a side branch of the car first $20 \mathrm{ml}$ of hyperkalaemic blood perfused antegradely for two minutes at a utes retrogradely at $150-200 \mathrm{ml} / \mathrm{min}$ (retrograde pressure $<40 \mathrm{~mm} \mathrm{Hg}$ ). Subsequently, continuous perfusion was maintained with a retrograde perfusion flow rate of $150 \mathrm{ml} / \mathrm{min}$,

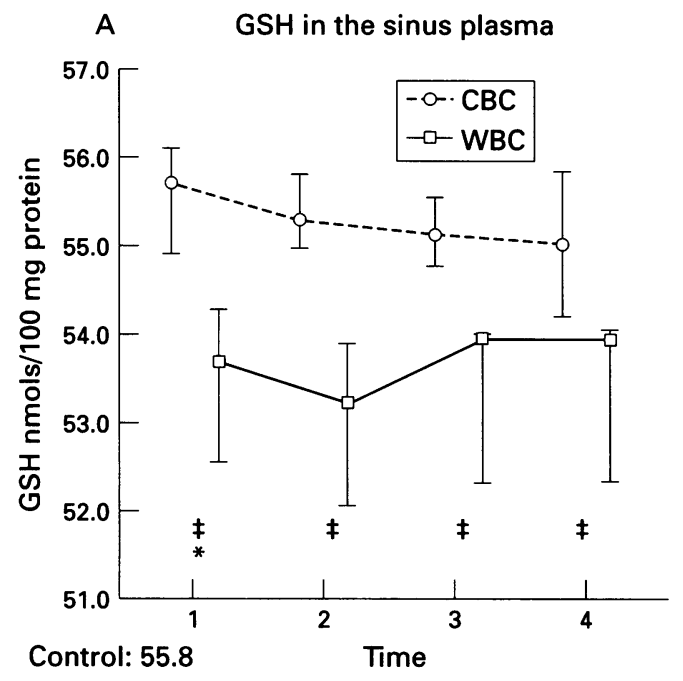

C Cys-SG in the coronary sinus plasma

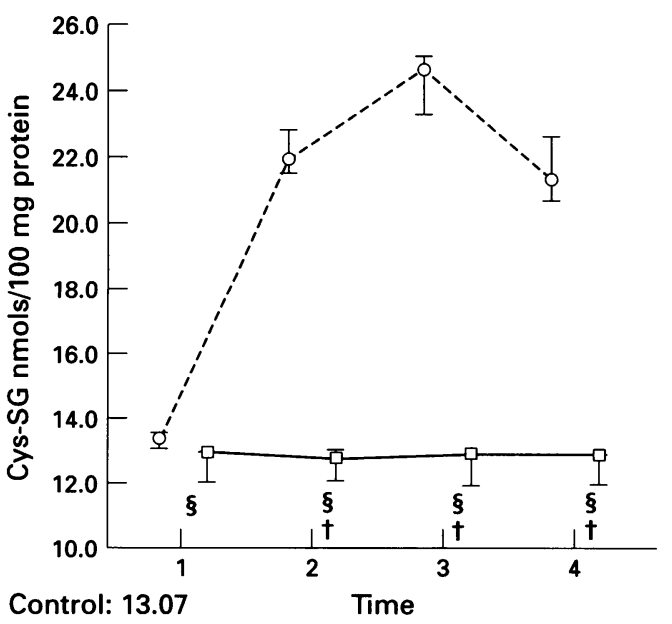

B GSSG in the coronary sinus plasma

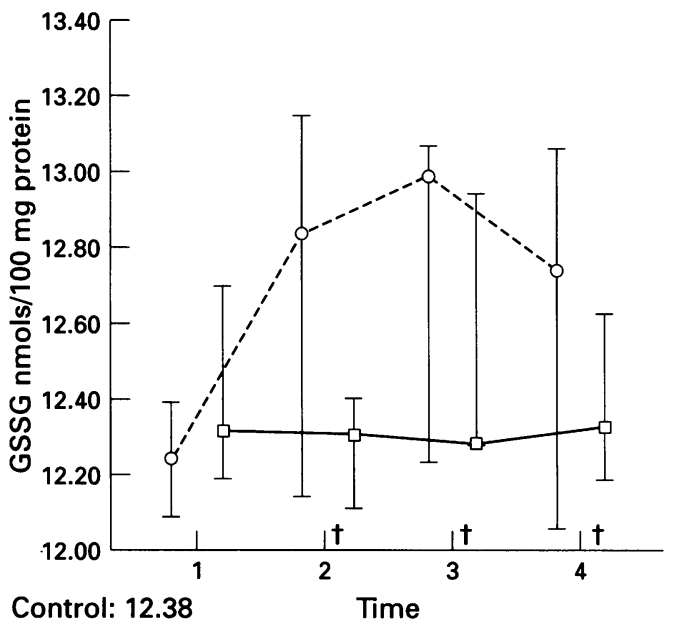

D Ratio in the coronary sinus plasma

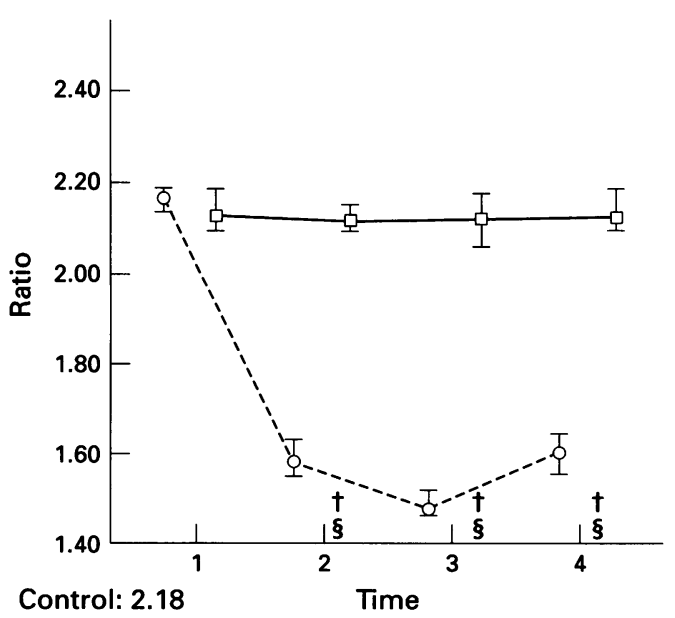


Figure 2 Modifications of the glutathione redox status in the peripheral vein plasma during cardioplegic arrest and reperfusion. Data are reported as median, 25th, and 75 th centile. $T 1$,

Before cardioplegia and the start of cardiopulmonary bypass; T2, one minute before aortic unclamping; T3, 15 minutes after aortic unclamping and reperfusion; T4, 30 minutes after aortic unclamping reperfusion. GSH, reduced glutathione GSSG, oxidised glutathione; Cys-SG, glutathione-cysteine mixed disulphide; Ratio, $G S H /(G S S G+C y s-S G)$ $C B C$ group, intermittent blood cardioplegia and warm modified reperfusion WBC group, continuous warm blood cardioplegia. ${ }^{\star} C B C$ values significantly different from control $(P<0.05) ; \dagger C B C$ values significantly different from T1 $(P<0.05) ; \ddagger C B C$ values significantly different from $W B C$ $(P<0.03) ; \$ C B C$ values significantly different from WBC $(P<0.01)$.
A GSH in the peripheral vein plasma

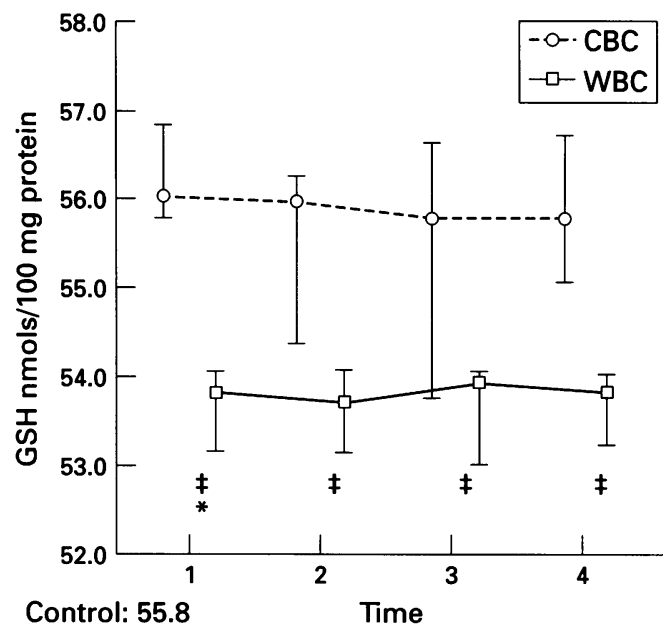

C Cys-SG in the peripheral vein plasma

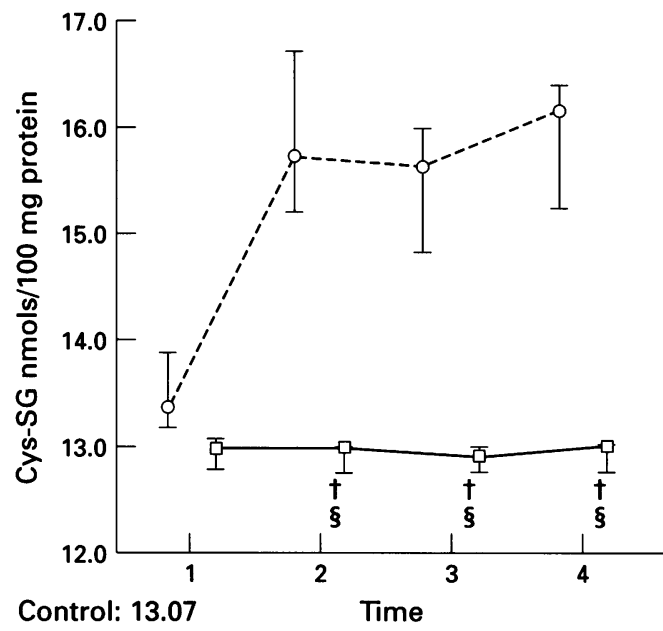

removed and divided into aliquots, and stored at $-80^{\circ} \mathrm{C}$. Before GSH measurements, $0.5 \mathrm{ml}$ of plasma were energetically mixed with $50 \mathrm{ml}$ of $60 \%$ perchloric acid. The plasma and the whole blood precipitates were removed by high speed centrifugation $(17000 \times g$ for 10 minutes) and the supernatant used for GSH assay. The samples were analysed by HPLC using an NH2 m-Bondpak column, a step gradient of methanol-ammonium acetate-acetic acid and spectrophotometric detection at 365 nm. GSH, GSSG, and Cys-SG were measured by identifying the corresponding peaks which were compared with a calibration curve obtained with pure standards. Concentrations of plasma GSH, GSSG, and Cys-SG were expressed as nmol/100 $\mathrm{mg}$ protein.

Sampling times were: before cardioplegia and before the start of cardiopulmonary bypass (T1); one minute before aortic unclamping (T2); 15 minutes after aortic unclamping and reperfusion (T3); and 30 minutes after aortic unclamping and reperfusion (T4).

\section{HAEMODYNAMIC AND METABOLIC}

MEASUREMENTS

Haemodynamic and metabolic measurements, by thermodilution technique, were: heart rate,
B GSSG in the peripheral vein plasma

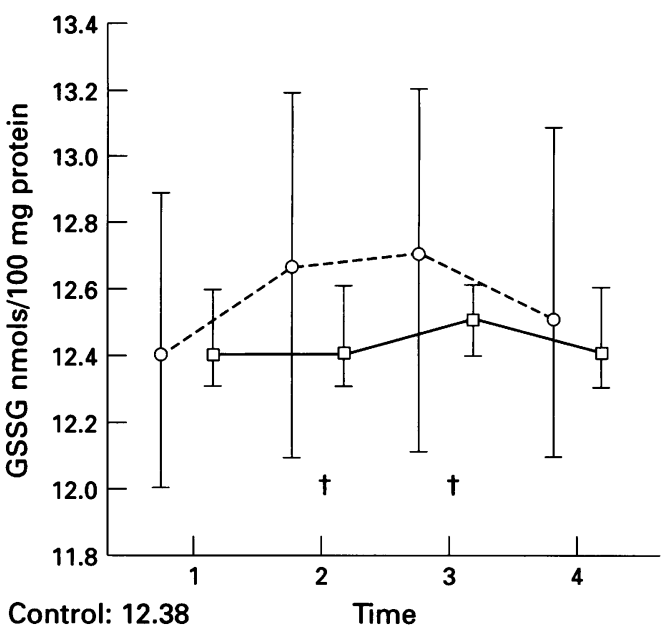

D Ratio in the peripheral vein plasma

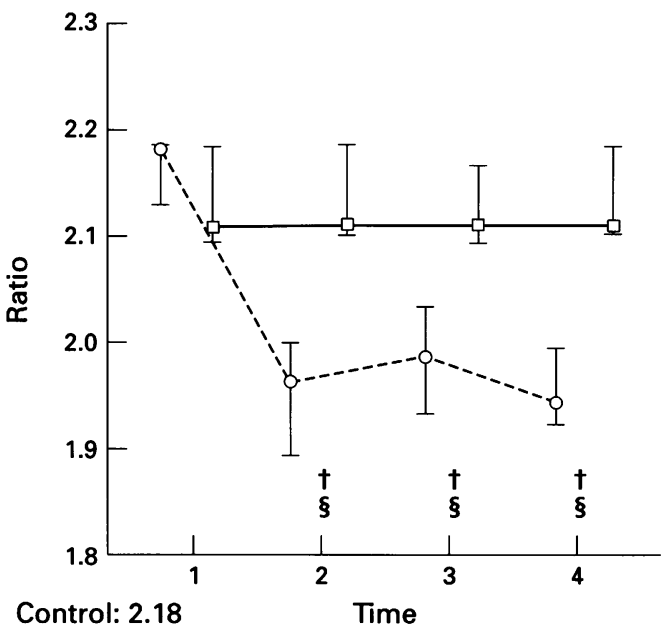

left atrial pressure (LAP), mean systemic arterial pressure (MAP), and cardiac output. Cardiac index (CI), left ventricular stroke work index (LVSWI), systemic vascular resistance (SVR), and $\mathrm{O}_{2}$ delivery were determined by standard formulas. From LVSWI and LAP, we calculated the ventricular function (VF), according to the following equation:

$$
\mathrm{VF}=11 \operatorname{artg}(\log \mathrm{LVSW}-1) / \log \mathrm{LAP}
$$

where artg is the trigonometric function arctangent. VF is an index of left ventricular performance that describes the ventricular stroke work as a function of filling pressure. ${ }^{27}$

Arterial and mixed venous blood were analysed immediately at $37^{\circ} \mathrm{C}$ for blood gases and $\mathrm{pH}$ (ABL4, Radiometer, Copenhagen, Denmark). In particular, partial oxygen pressure in mixed venous blood $\left(\mathrm{PVO}_{2}\right)$ and arteriovenous oxygen difference $\left(\mathrm{avO}_{2} \mathrm{D}\right)$ were measured. Haemoglobin and oxygen saturation were measured directly (IL 482 CoOximeter System, Instrumental Laboratory, Lexington, Massachusetts, USA). Oxygen content was calculated from the formula:

$\mathrm{O}_{2}$ content $=1.36 \mathrm{Hb}^{\star} \mathrm{S}+0.0031 \mathrm{PO}_{2}$ where $\mathrm{PO}_{2}$ is the partial oxygen pressure.

A carbon dioxide analyser (930 Siemens 
Figure 3 Modifications of the glutathione redox status in whole blood from the coronary sinus and peripheral vein during cardioplegic arrest and reperfusion. Data are reported as median, 25 th, and 75 th centile. $T 1$,

Before cardioplegia and the start of cardiopulmonary bypass; T2, one minute before aortic unclamping; T3, 15 minutes after aortic unclamping and reperfusion; T4, 30 minutes after aortic unclamping reperfusion. GSH, reduced glutathione; GSSG, oxidised

glutathione; Cys-SG

glutathione-cysteine mixed disulphide; Ratio,

$G S H /(G S S G+C y s-S G)$.

$C B C$ group, intermittent

blood cardioplegia and

warm modified reperfusion; WBC group, continuous warm blood cardioplegia. ${ }^{\star} C B C$ values significantly different from control

$(P<0.05) ;+C B C$ values significantly different from T1 $(P<0.05)$; $¥ C B C$

values significantly

different from WBC

$(P<0.03) ; \$ C B C$ values significantly different from WBC $(P<0.002)$;

${ }^{*} C B C$ values

significantly different from WBC $(P<0.01)$
A GSH in the coronary sinus whole blood

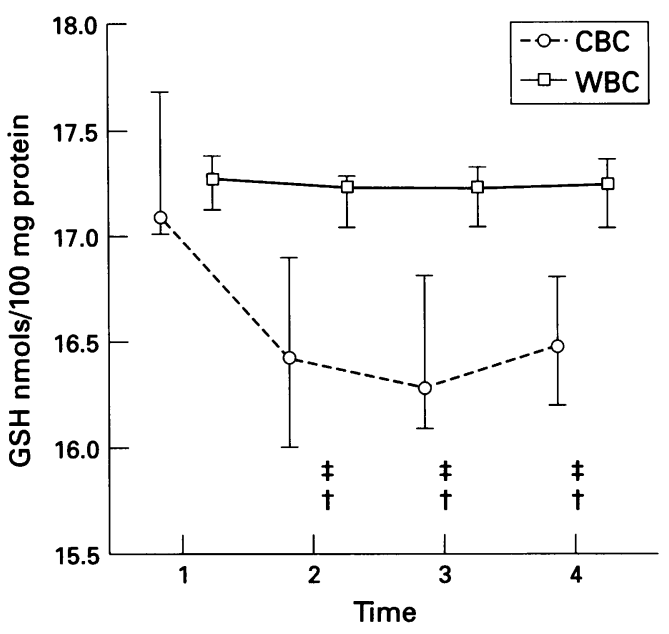

C GSH in the peripheral vein whole blood

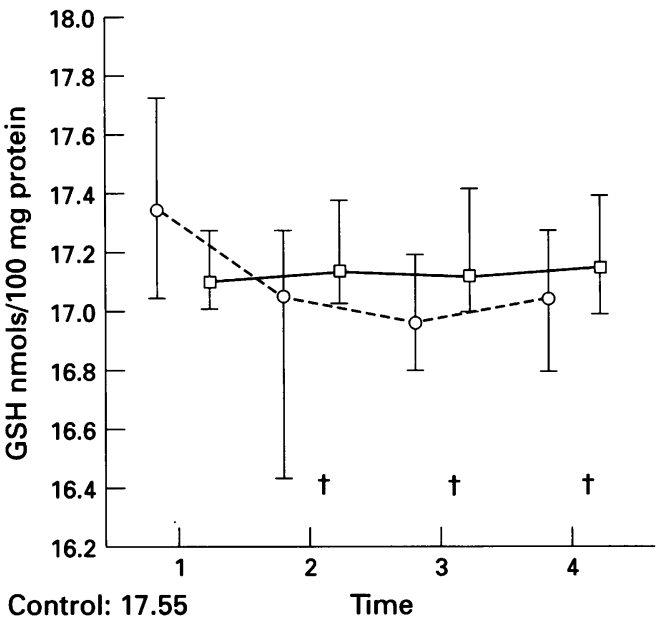

Elema, Sweden) connected to the ventilator (900 C, Siemens Elema) was used to record continuously end-tidal carbon dioxide and minute carbon dioxide production index $\left(\mathrm{VCO}_{2} \mathrm{I}\right)$. Haemodynamic and metabolic data were collected from a total of 100 patients (including the two study groups) for each cardioplegic technique, selected, and randomised according to the aforementioned criteria. Blood specimens were also obtained to analyse cardiac enzymes: total serum activities of creatine kinase were determined by an enzymatic method and the activity of creatine kinase MB isoenzyme was measured by immunoassay. Measurements were recorded: before induction of anaesthesia (T1), before sternotomy (T2), at admission to the intensive care unit (T3), and at 3, 6, 9, and 24 hours after ICU admission (T4, T5, T6, T7). After discontinuation of cardiopulmonary bypass, measurements were obtained when the patients were haemodynamically stable.

STATISTICAL ANALYSIS

The median and the 25 th and 75 th centile of each variable of the glutathione redox status was determined, the median values compared using the rank Mann-Whitney test. The mean (SD) of haemodynamic parameters were sup-
B GSSG in the coronary sinus whole blood

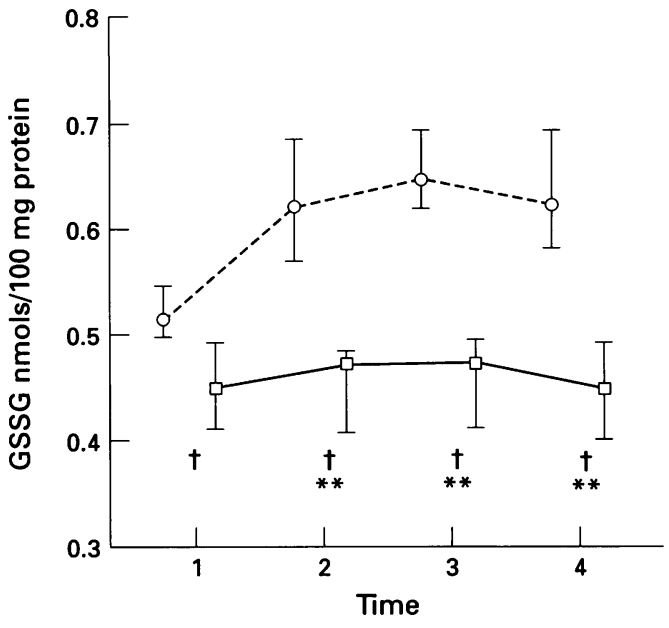

D GSSG in the peripherial vein whole blood

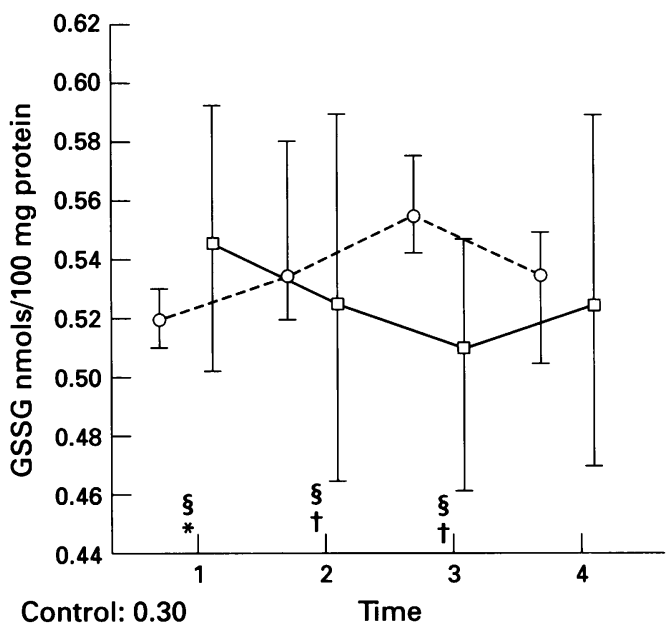

plied and a modified $t$ test (Student-NewmanKeuls) and $\chi^{2}$ test for the two groups was applied. ANOVA linear regression analysis was applied to correlate enzymes versus Cys-SG measurements, and cross clamping time versus glutathione redox balance.

\section{Results}

The groups (table 1) overlapped in respect to vessel disease and left ventricular preoperative class, even the expected difference in cardiopulmonary bypass time for different rewarming times was not significant. Minor differences were observed in creatine kinase and $M B$ isoenzyme concentrations.

The modifications of glutathione redox status in the coronary sinus and peripheral vein plasma of patients undergoing the two different methods of myocardial protection are shown in figures 1 and 2.

Neither group had a significant decrease of coronary sinus plasma GSH from T1 to T4. In the CBC group, GSSG and CyS-SG concentrations increased and remained sustained for at least for 30 minutes after reperfusion, and the overall redox balance of glutathione decreased markedly. The difference was statistically significant for GSSG at T2, T3, and T4 
Table 2 Changes in physiological variables after cardiopulmonary bypass

\begin{tabular}{|c|c|c|c|c|c|c|c|}
\hline & $T 1$ & $T 2$ & T3 & $T 4$ & $T 5$ & T6 & $T 7$ \\
\hline 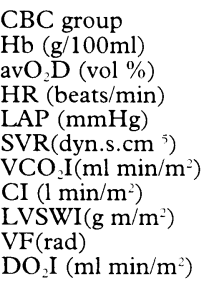 & $\begin{array}{c}12.9(1 \cdot 3) \\
3.4(0 \cdot 6) \\
71 \cdot 3(17 \cdot 3) \\
10 \cdot 2(2 \cdot 6) \\
1291(432) \\
3 \cdot 3(1 \cdot 1) \\
60 \cdot 4(11 \cdot 7) \\
8 \cdot 8(0 \cdot 9) \\
304(110)\end{array}$ & $\begin{array}{c}13 \cdot 0(1 \cdot 3) \\
4 \cdot 8(1 \cdot 1) \\
71 \cdot 3(10 \cdot 6) \\
10 \cdot 0(3 \cdot 1) \\
1559(264) \\
280(39) \\
2 \cdot 2(0 \cdot 3) \\
35 \cdot 5(5 \cdot 3) \\
7 \cdot 6(0 \cdot 9) \\
222(30)\end{array}$ & $\begin{array}{c}9 \cdot 3(1 \cdot 5) \\
4 \cdot 6(0 \cdot 8) \\
94 \cdot 5(16 \cdot 9) \\
9 \cdot 2(3 \cdot 7) \\
1790(472) \\
192(45) \dagger \\
2 \cdot 2(0 \cdot 6) \\
30 \cdot 8(10) \\
7 \cdot 5(2 \cdot 4) \\
158(35) \dagger\end{array}$ & $\begin{array}{c}9 \cdot 6(1 \cdot 2) \\
5 \cdot 2(0 \cdot 9) \\
106(14 \cdot 6) \\
11 \cdot 1(2 \cdot 6) \\
1075(293) \\
306(85) \\
2 \cdot 9(0 \cdot 6) \\
30 \cdot 4(8 \cdot 8) \\
6 \cdot 7(1 \cdot 4) \\
213(42)\end{array}$ & $\begin{array}{c}8 \cdot 9(1 \cdot 5) \\
4 \cdot 4(0 \cdot 7) \\
106(19 \cdot 3) \\
11 \cdot 4(3 \cdot 2) \\
1017(233) \\
287(55) \\
3(0 \cdot 5) \\
30 \cdot 5(6 \cdot 6) \\
6 \cdot 8(1 \cdot 2) \\
209(39)\end{array}$ & $\begin{array}{c}8 \cdot 9(1 \cdot 3) \\
4 \cdot 0(0 \cdot 5)^{\star} \\
106(15 \cdot 0) \\
10 \cdot 6(2 \cdot 2) \\
1015(271) \\
270(51) \\
3 \cdot 1(0 \cdot 5) \\
31 \cdot 2(5 \cdot 0) \\
7(1 \cdot 0) \\
212(27)\end{array}$ & $\begin{array}{c}9 \cdot 6(0 \cdot 9) \\
4 \cdot 3(0 \cdot 8) \\
100(9 \cdot 1) \\
10 \cdot 4(3 \cdot 4) \\
1310(275)^{\star} \\
\\
2 \cdot 9(0 \cdot 5) \\
37(10 \cdot 0) \\
7 \cdot 4(1 \cdot 1) \\
208(46)\end{array}$ \\
\hline $\begin{array}{l}\text { WBC group } \\
\mathrm{Hb}(\mathrm{g} / 100 \mathrm{ml}) \\
\text { avO D }(\mathrm{vol} \%) \\
\mathrm{HR}(\mathrm{b} / \mathrm{min}) \\
\mathrm{LAP}(\mathrm{mmHg}) \\
\text { SVR }\left(\text { dyn.s.cm }{ }^{5}\right) \\
\text { VCO } \mathrm{I}\left(\mathrm{ml} \mathrm{min} / \mathrm{m}^{2}\right) \\
\mathrm{CI}\left(1 \mathrm{~min} / \mathrm{m}^{2}\right) \\
\mathrm{LVSWI}\left(\mathrm{g} \mathrm{m} / \mathrm{m}^{2}\right) \\
\text { VF }(\mathrm{rad}) \\
\mathrm{DO}_{2} \mathrm{I}\left(\mathrm{ml} \mathrm{min} / \mathrm{m}^{2}\right)\end{array}$ & $\begin{array}{c}12 \cdot 8(1 \cdot 1) \\
3 \cdot 4(0 \cdot 7) \\
68 \cdot 2(9 \cdot 5) \\
10 \cdot 2(4 \cdot 7) \\
1297(427) \\
3 \cdot 2(0 \cdot 8) \\
63(17 \cdot 7) \\
9 \cdot 1(0 \cdot 8) \\
255(54)\end{array}$ & $\begin{array}{c}12 \cdot 6(0 \cdot 8) \\
4 \cdot 7(0 \cdot 6) \\
66 \cdot 8(8 \cdot 5) \\
10 \cdot 3(4 \cdot 0) \\
1555(525) \\
231(43) \\
2 \cdot 1(0 \cdot 4) \\
32 \cdot 6(7 \cdot 5) \\
7 \cdot 3(1 \cdot 2) \\
182(38)\end{array}$ & $\begin{array}{c}10 \cdot 1(1 \cdot 2) \\
4 \cdot 9(0 \cdot 9) \\
104(18 \cdot 5) \\
10 \cdot 1(2 \cdot 8) \\
1521(455) \\
234(37) \\
2 \cdot 6(0 \cdot 7) \\
33 \cdot 4(9 \cdot 1) \\
7 \cdot 3(0 \cdot 6) \\
201(60)\end{array}$ & $\begin{array}{c}9 \cdot 9(1 \cdot 2) \\
4 \cdot 8(0 \cdot 9) \\
101(12 \cdot 8) \\
10 \cdot 1(2 \cdot 8) \\
1155(364) \\
291(60) \\
2 \cdot 7(0 \cdot 5) \\
29 \cdot 4(4 \cdot 2) \\
6 \cdot 9(0 \cdot 6) \\
213(75)\end{array}$ & $\begin{array}{c}9 \cdot 4(1 \cdot 3) \\
4 \cdot 4(0 \cdot 9) \\
95 \cdot 3(8 \cdot 8) \\
10 \cdot 8(2 \cdot 4) \\
1120(349) \\
293(53) \\
2 \cdot 9(0 \cdot 7) \\
32 \cdot 7(9 \cdot 5) \\
7(0 \cdot 7) \\
209(70)\end{array}$ & $\begin{array}{c}9 \cdot 1(1 \cdot 3) \\
4 \cdot 6(1 \cdot 0) \\
91 \cdot 4(10 \cdot 6) \\
9 \cdot 9(2 \cdot 7) \\
1016(263) \\
281(58) \\
3 \cdot 0(0 \cdot 4) \\
34 \cdot 0(5 \cdot 8) \\
7 \cdot 5(0 \cdot 6) \\
208(48)\end{array}$ & $\begin{array}{r}9 \cdot 4(1 \cdot 4) \\
3 \cdot 9(0 \cdot 6) \\
89 \cdot 6(7 \cdot 3) \\
11 \cdot 2(2 \cdot 4) \\
986(394) \\
\\
3 \cdot 3(0 \cdot 6) \\
39 \cdot 5(7 \cdot 4) \\
7 \cdot 5(0 \cdot 6) \\
223(45)\end{array}$ \\
\hline
\end{tabular}

Values are reported as mean (SD). *Significantly different $(\mathrm{P}<0.03)$ from the WBC group; + Significantly different $(\mathrm{P}<0.01)$ from the WBC group.

$\mathrm{T} 1$, before anaesthesia induction, T2 before sternotomy; T3, at the admission in the intensive care unit; T4-T7, at 3, 6, 9, 24 hours later. CBC group, intermitten blood cardioplegia and warm modified reperfusion; WBC group, continuous warm blood cardioplegia. Hb, haemoglobin; avO $\mathrm{O}_{2} \mathrm{D}$, arteriovenous oxygen difference; $\mathrm{HR}$, heart rate; LAP, left atrial pressure; SVR, systemic vascular resistances; VCO ${ }_{2} \mathrm{I}$, minute carbon dioxide production index; CI, cardiac index; LVSWI, left ventricular stroke work index; $\mathrm{VF}$, ventricular function; $\mathrm{DO}_{2} \mathrm{I}$, oxygen delivery index.

versus $\mathrm{T} 1$, for CyS-SG and for the ratio (GSH/(GSSG + Cys-SG)) at T2, T3, and T4 versus $\mathrm{T} 1$ and compared with the WBC group in which glutathione redox status was almost unmodified (fig 1). In addition, only the CBC group showed similar but not so substantial modifications of the same variables in parallel measurements performed on plasma obtained from a peripheral vein (fig 2).

However, none of these parameters in either group was significantly correlated with the duration of cardioplegic arrest (cross clamping time) or the cardiospecific enzymes (creatine kinase $\mathrm{MB}$ isoenzyme) (correlation coefficient $<0.40, \mathrm{P}>0.5)$.

The modifications of glutathione redox status in whole blood (erythrocytes) are shown in

Figure 4 Most significant variables as a percentage of basal time at each observation time in the two groups. T1, before

anaesthesia induction; $T 2$, before sternotomy; T3, at admission to intensive care unit; T4-T7, 3, 6, 9, and 24 hours later. $C B C$ group, intermittent blood cardioplegia and warm modified reperfusion; WBC group, continuous warm blood cardioplegia, $S V R$, systemic vascular resistance; LVSWI, left ventricular stroke work index; $D O_{2} I$, oxygen delivery index; VCO I, minute carbon dioxide production index.

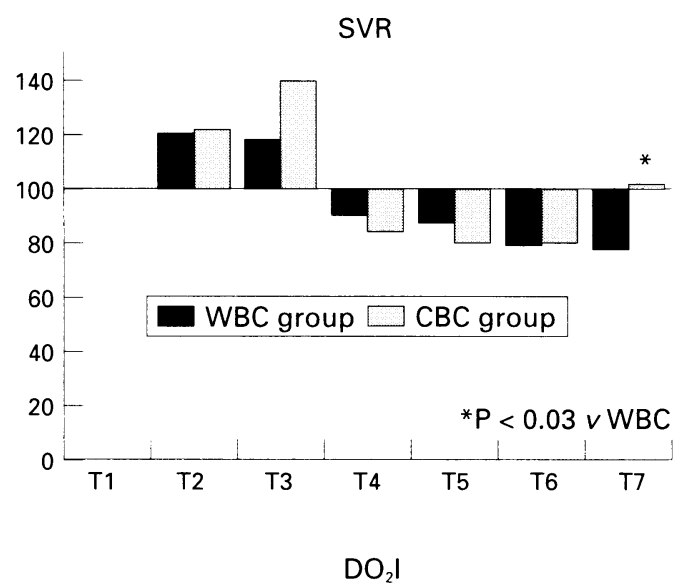

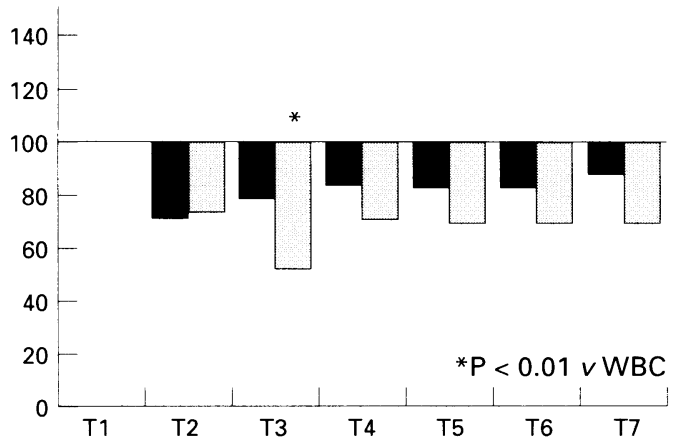

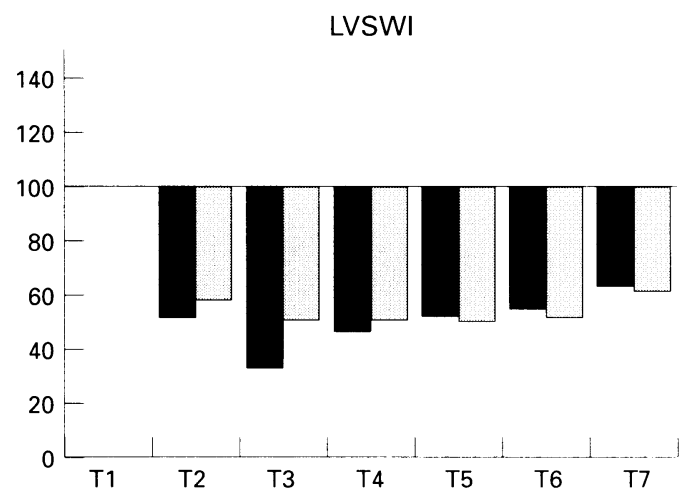

figure 3. Heart reperfusion after cardioplegia was associated with a moderate decrease of GSH and a concomitant increase of GSSG in the coronary sinus whole blood of the CBC group. These differences were significant for $\mathrm{T} 1$ versus $\mathrm{T} 2, \mathrm{~T} 3$, and $\mathrm{T} 4$, and compared with the WBC group at same times. Only minor variations were observed in the peripheral venous blood of the CBC group, while no significant differences were measured in the coronary sinus and peripheral venous whole blood of the WBC group at any time.

Table 2 and figure 4 show the haemodynamic changes after cardiopulmonary bypass for the two groups. Recovery progressively improved during the six hours after ICU admission. LVSWI remained lower than pre-

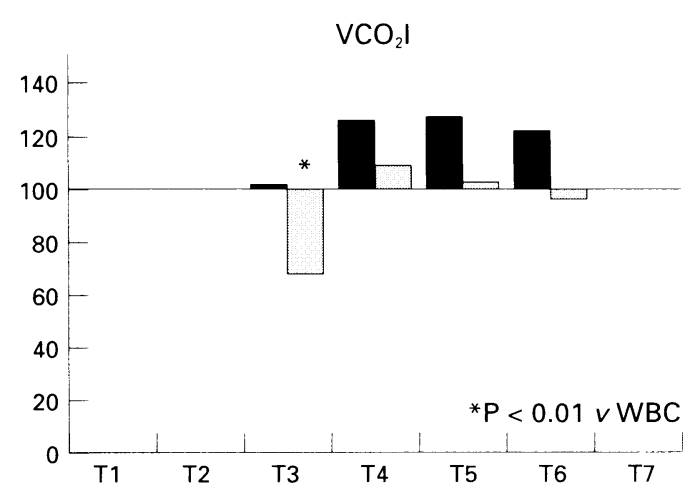


bypass values while CI, LAP, SVR, $\mathrm{O}_{2}$ delivery and $\mathrm{avO}_{2} \mathrm{D}$ values initially indicated good cardiovascular performance without statistically significant differences between the two groups, especially at 24 hours after CABG.

\section{Discussion}

Our knowledge of myocardial stunning and the involvement of free radicals in postischaemic injury in human heart has been relatively elusive compared with the amount of experimental data. ${ }^{151719}$ Whether reperfusion injury is clinically relevant in patients undergoing myocardial reperfusion after global ischaemia during cardioplegic arrest (cardiac surgery), or after thrombolytic or angioplasty therapy for myocardial infarction remains controversial. ${ }^{28-30}$ Postoperative acute myocardial dysfunction has been suggested to be a common occurrence after cardiopulmonary bypass. ${ }^{1-3}$ It appears to be a reversible event within 24 hours of surgery and may have importance in the early postoperative period, especially in patients whose ventricular function is already compromised. Some studies have suggested that inadequate myocardial protection or cold cardioplegia ${ }^{31} 32$ together with reperfusion injury from oxygen derived free radicals are factors in postoperative myocardial dysfunction. ${ }^{334}$ Because reperfusion is a prerequisite for the survival of ischaemic tissue, the proof of the existence of reperfusion induced injury essentially relies on the demonstration of limitation of myocardial injury by interventions that are implemented at the time of reperfusion. However, we are waiting confirmation that stunning indicates injury at the time of reperfusion rather than being a sign of delayed recovery after ischaemia. ${ }^{135-37}$

The method of myocardial protection developed by Lichtenstein et $a l^{22}$ that involves chemical electromechanical arrest and continuous warm blood perfusion aims to prevent damage from ischaemia, hypothermia, reperfusion, and oxidative stress.

As reported by Sies $^{38}$ oxidative stress can be defined as a condition in which the balance between pro-oxidants and antioxidants is shifted in favour of the former: among the various intracellular antioxidants an important role is played by GSH that acts as a reductant in enzymatic reactions catalysed by peroxidase and thiol disulphide oxidoreductases. ${ }^{39} 40$ Glutathione exists in three forms: GSH (reduced), GSSG (oxidised), and Cys-SG (glutathione mixed disulphides with low molecular weight thiols such as cysteine) or with thiol residues in protein. ${ }^{41}$ Intracellular glutathione concentrations, kept in the millimolar range by continuous synthesis, and the redox ratio between GSH, and GSSG and Cys-SG are usually extremely high. The redox balance is different in extracellular fluids (plasma) where the concentrations of GSSG and mixed disulphides are relatively high. However, following oxidative stress, GSH is enzymatically oxidised to GSSG which, in turn, may be rereduced or actively excreted from the cell. ${ }^{42}$
For these reasons an increased concentration of GSSG and a decrease of the glutathione redox balance in intracellular as well as extracellular fluids have been proposed as suitable indexes of oxidative stress. ${ }^{43}$

The present study intended to demonstrate that postcardioplegia free radical production was detectable in patients undergoing cardiac surgery and that reduction (or suppression) of oxidative stress could be achieved by avoiding or limiting ischaemia and consequently reducing reperfusion injury without supplying antioxidants or modifications of constituents of cardioplegia as used in recent years. ${ }^{23}$

The results from the CBC group show that during reperfusion of ischaemic human hearts the plasma concentrations of the oxidised form of glutathione increased in the coronary sinus, indicating oxidative stress, while the WBC group did not show any important alterations in the glutathione redox status, suggesting that this method minimises the effects of ischaemia and prevents additional damage from hypothermia and reperfusion.

A moderate but significant decrease in the basal concentration of GSH was found in the WBC group in both coronary sinus and peripheral vein plasma compared with control subjects (figs 1 and 2). As the decrease was not parallelled by a concomitant increase of the oxidised forms of glutathione, one can argue that this was a decreased supply rather than oxidation.

It has been claimed ${ }^{19-2738-4144}$ that erythrocytes are a natural circulating reservoir of antioxidants to be employed during oxidative stress in various organs and tissues. A change in erythrocyte glutathione redox status during reperfusion would therefore reflect both the occurrence of an oxidative stress and the involvement of erythrocyte glutathione as an antioxidant defence mechanism. More than $98 \%$ of total blood glutathione is in the erythrocytes, therefore, a simple measure of total blood glutathione reflects the concentration of glutathione in erythrocytes.

Plasma glutathione measurements are mirrored in whole blood from either the coronary sinus or the peripheral vein, showing an increase of oxidised forms only in the CBC group (fig 3). Furthermore, a significant increase of GSSG was detected in whole blood (coronary sinus and peripheral vein) from both groups before cardioplegic arrest compared with controls (fig 3B). This difference could be related to the induction of anaesthesia, and aortic and caval cannulation as a global "stress"; however, during reperfusion the concentration of GSSG markedly increased in the CBC group especially in whole blood from the coronary sinus.

Signs of oxidative stress were also found in peripheral blood from the CBC group and this may reflect either a lesser increase of oxidised forms in the peripheral vein secondary to an initial greater generation at the myocardium, or the involvement of other tissues in the oxidative process related to general activation of polymorphonuclear leucocytes by cardiopulmonary bypass. The first hypothesis is 
more likely because this increase in oxidised forms was not detected in the peripheral blood of the WBC group that underwent similar cardiopulmonary bypass.

Another criticism could be related to the difference in the delivery technique: intermittent versus continuous. Washout is usually a matter of concern, but the evaluation times chosen, particularly 15 and 30 minutes after reperfusion, provided comparable washout for the two techniques.

The correlation between the extent of free radical production and the duration of ischaemia has been investigated in in vivo and in vitro experimental postischaemia mod$\mathrm{els}^{8546}$ and more recently in postcardioplegic arrest in humans hearts..$^{20}$ In the present study there was no statistically significant correlation between the duration of ischaemia and the appearance of biological signs of oxidative stress in either group. This can be taken as additional proof of the antioxidant efficacy of blood in the cardioplegic solution ${ }^{1944}$ especially for the CBC group. Blood appears attractive from the standpoint of inherent mechanisms for prevention of free radical generation: in addition to the antioxidants contained in plasma (urate, plasma proteins, ascorbate, vitamin E), erythrocytes contain catalase, superoxide dismutase, and glutathione all of which participate in reactions to scavenge free radicals. Indeed, no major efflux of GSH (mainly related to unspecified membrane damage) from reperfused hearts was detected in either cardioplegia group in contrast with other reports where crystalloid cardioplegia was employed. ${ }^{17}$ The demonstration that erythrocyte glutathione is oxidised to GSSG proves that intra-erythrocyte antioxidant defences are actively engaged during reperfusion of the CBC group.

The role of hypothermia as a protective agent during cardioplegic arrest is controversial; hypothermia seems to alter tissue oxygen delivery and reduce the cell's ability to produce ATP efficiently after a period of anaerobic arrest. ${ }^{22}{ }^{46}$ Furthermore, it is widely known that the activities of many enzymes involved in crucial metabolic pathways or free radical detoxification are inhibited by low tissue temperature. ${ }^{31}$

The most meaningful finding in our series was the lack of correlation between oxidative stress and immediate postoperative ventricular dysfunction; indeed there was no significant difference between groups in common haemodynamic parameters (table 2 and fig 4 ) or need of pharmacological or mechanical support. Even if the differences of $\mathrm{DO}_{2} \mathrm{I}$ and $\mathrm{VCO}_{2} \mathrm{I}$ three hours after ICU admission (T3) could be due to the lower metabolic debt, lower peripheral vasoconstriction and better tissue perfusion of the WBC compared with the CBC group, the latter also showed improved and uneventful post-surgical courses.

We could perhaps concur with $\mathrm{Ki}-\mathrm{Bong}^{47}$ that oxygen free radicals play an important role in in vivo myocardial reperfusion stress, but endogenous self-defensive antioxidative enzyme systems are also triggered leading to significant myocardial cellular damage. Indeed the complete reduction of that oxidative stress does not affect the postoperative recovery of myocardial function in a low risk carefully selected group of patients. Additional studies are required to assess the contribution of free radicals to the clinical pathology associated with surgical procedures in high risk patients where the presence of postoperative myocardial stunning can significantly affect mortality and morbidity.

The work has been supported in part by MURST $60 \%$ grant. We thank Miss Laura Berto for preparation of the graphics and manuscript.

1 Breisblatt WM, Stein KL, Wolfe CJ, Follansbee WP, Capozzi J, Armitrage JM, et al. Acute myocardial dysfunction and recovery: a common occurrence after coronary bypass surgery. $\mathcal{F}$ Am Coll Cardiol 1990;15:1261-9.

2 Mangano DT. Biventricular function after myocardial revascularization in humans: deterioration and recovery patterns during the first 24 hours. Anesthesiology 1985 62:571-7.

3 Bolli R, Haortley CJ, Chelly JE, Patel BS, Rabinovitz RS, Jerondi MO, et al. An accurate non-traumatic ultrasonic method to monitor myocardial wall thickening in patients undergoing cardiac surgery. $\mathcal{f}$ Am Coll Cardiol 1990;15 1055-65.

4 Vinten-Johansen J, Chiantella V, Johnston WE, Jolly BT, Kendricks WD, Hester TO, et al. Adjuvant N-(2-mercaptopropionyl)-glycine in blood cardioplegia does not improve myocardial protection in ischemically damaged hearts. F Thorac Cardiovasc Surg 1990;100:65-76.

5 Rosenkranz ER, Vinten-Johansen J, Buckberg GD, Okamoto F, Edwards H, Bugyi H. Benefits of normothermic induction of blood cardioplegia in energy-depleted hearts, with maintenance of arrest by multidose cold
blood cardioplegic infusions. $\mathcal{f}$ Thorac Cardiovasc Surg 1982;84:667-77.

6 Wilson IC, Gardner TJ. Stunned myocardium in cardiac surgery. In: Goldhaber SZ, Bounameaux H, eds. Stunned myocardium. Properties, mechanisms, and clinical manifestations. New York: Marcel Dekker, 1982:379-99.

7 Gardener TJ. Oxygen radicals in cardiac surgery. Free Radic Biol Med 1988;4:45-50.

8 Bolli R, Patel BS, Jeroudi MO, Lai KE, McCay PB. Demonstration of free radical generation in "stunned" myocardium of intact dogs with the use of the spin trap alpha-phenyl-N-tert-butyl nitrone. $\mathcal{F}$ Clin Invest 1988;82 476-85.

9 Zweier JL, Kuppusamy P. Electron paramagnetic resonance measurements of free radicals in the intact beating heart: a technique for detection and characterization of free radicals in whole biological tissues. Proc Natl Acad Sci USA 1988;85:5703-7.

10 Garlick PB, Davies MJ, Hearse DJ, Slater TF. Direct detection of free radicals in the reperfused rat heart using electron spin resonance spectroscopy. Circ Res 1987;61: 757-60.

11 Myers ML, Bolli R, Lekich RF, Hartley CJ, Roberts R Enhancement or recovery of myocardial function by oxyEnhancement or recovery of myocardial function by oxygen free-radical scavengers after re
ischaemia. Circulation 1985;72:915-21.

12 Przyklenk K, Kloner RA. Superoxide dismutase plus catalase improve contractile function in the canine model of the "stunned myocardium". Circ Res 1986;58:148-56.

13 Bolli R, Jeroudi MO, Patel BS, Aruoma OI, Halliwell B Lai KE, et al. Marked reduction of free radical generation and contractile dysfunction by antioxidant therapy begun at the time of reperfusion. Evidence that myocardia "stunning" is a manifestation of reperfusion injury. Circ Res 1989;65:607-22.

4 Del Nido PJ, Mickle DAG, Wilson GJ. Evidence of myocardial free radical injury during elective repair or tetralogy of Fallot. Circulation 1987;76(suppl 4):174-9.

15 Weisel RD, Mickle DAG, Finkle CD, Tumiati LC Madonik MM, Ivanov J, et al. Myocardial free-radical injury after cardioplegia. Circulation 1989;80(suppl III) 14-8.

16 Menasche P, Pasquier C, Jaillon P, Piwinica A. Deferoxamine reduces neutrophil-mediated free radical production during cardiopulmonary bypass in man. $f$ production during cardiopulmonary Cardiovasc Surg 1988;96:582-9.

17 Ferrari R, Alfieri O, Curello S, Ceconi C, Cargnoni A, Marzollo P, et al. Occurrence of oxidative stress during Marzollo P, et al. Occurrence of oxidative stress during reperfusion.

18 Fabiani JN, Farah B, Vuilleminot A, Lecompte T, Emerit I, Chardigny C, et al. Chromosomal aberrations and neutrophil activation induced by reperfusion in the ischaemic trophil activation induced by reperfusion in the isch
human heart. Eur Heart $\mathcal{f}$ 1993;14(suppl G):12-7.

19 Lapenna D, Mezzetti A, De Gioia S, Pierdomenico SD, Verna AM, Danielle F, et al. Blood cardioplegia reduces oxidant burden in the ischemic and reperfused human oxidant burden in the ischemic and reperfused
myocardium. Ann Thorac Surg 1994;57:1522-5. 
20 Tortolani AJ, Powell SR, Misik V, Weglicki WB, Pogo GJ, Kramer JH. Detection of alkoxyl and carbon-centered free radicals in coronary sinus blood from patients undergoing elective cardioplegia. Free Radic Biol Med 1993; 14:421-6.

21 Prasad K, Kalra J, Bharadwaj B, Chaudhary AK. Increased oxygen free radical activity in patients on cardiopulmonary bypass undergoing aortocoronary bypass surgery. Am Heart $¥ 1992 ; 123: 37-45$.

22 Lichtenstein SV, Ashe KA, El Delati H, Cusimano RJ, Panos A, Slutsky AS. Warm heart surgery. 7 Cardiovasc Surg 1991;101:269-74.

23 Buckberg GD. A proposed "solution" to the cardioplegic controversy. F Thorac Cardiovasc Surg 1979;77:803-15.

24 Buckberg GD. Anterograde-retrograde blood cardioplegia to ensure cardioplegic distribution: operative techniques and objectives. $¥$ Cardiac Surg 1989;4:216-38.

25 Page RD, Sharpe DA, Bellamy CM, Rashid A, Fabri BM Normothermic arrest with continuous hyperkalaemic blood: initial experience. Eur $f$ Cardiothorac Surg 1992;6: 461-8.

26 Reed DJ, Babson JR, Beatty PW, Brody AE, Ellis WW, Polley DW. High performance liquid chromatography analysis of hanomale levels of glutathione disulfide and related thiols and disulfides. Anal Biochem 1980;106: 55-62.

27 Siegel JH, Greenspan M, Del Guercio LRM. Abnormal vascular tone, defective oxygen transport and myocardial failure in human septic shock. Ann Surg 1967;165: 504-17.

28 Kloner RA, Przyklenk K, Rahimtoola SH, Braunwald E. Myocardial stunning and hibernation: mechanism and clinical implications. Heart Dis Clin Update 1990;11: 241-56.

29 Braunwald E. The stunned myocardium: newer insights into mechanisms and clinical applications. $f$ Thorac Cardiovasc Surg 1990;100:310-

30 Patel B, Kloner RA, Przyklenk K, Braunwald E. Postischemic myocardial "stunning": a clinically relevant phenomenon Ann Intern Med 1988;108:626-8.

31 Swanson DK, Myerowitz PD. Effect of reperfusion temperature and pressure on the functional and metabolic recovery of preserved hearts. $\mathcal{F}$ Thorac Cardiovasc Surg 1983;86:242-51.

32 Gold JP, Roberts AJ, Hoover EL. Effects of prolonged aortic cross clamping with potassium cardioplegia on myocardial contractility in man. Surg Forum 1979;30: $252-4$.

33 Bolli R. Oxygen-derived free radicals and postischemic myo- cardial dysfunction. 7 Am Coll Cardiol 1988;12:239-49.

34 Przyklenk K, Kloner RA. "Reperfusion injury" by oxygen derived free radicals? Circ Res 1989;64:86-96.

35 Bolli R. Oxygen-derived free radicals and myocardial reperfusion injury: an overview. Cardiovasc Drugs Ther 1991;5: 249-68.

36 Hearse DJ, Bolli R. Reperfusion-induced injury: manifestation, mechanisms and clinical relevance. Trends Cardiovasc Med 1992;26:101-8.

37 Hearse DJ. Reperfusion-induced injury: a possible role for oxidant stress and its manipulation. Cardiovasc Drug Ther 1991;5:225-36.

38 Sies H. Oxidative stress. London: Academic Press, 1985.

39 Larsson A, Orrenuis S, Holmgren A, Mannervik N. Functions of glutathione: biochemical, physiological, toxicological and clinical aspects. New York: Raven Press, 1983.

40 Tanigouchi N, Higashi T, Sakamoto Y, Meister A Glutathione centennial: molecular properties and clinical implications. New York: Accademic Press, 1989

41 Inoue M. In: Dolphin D, Paulson R, Avramovic JR, eds. Glutathione dynamic aspects of protein mixed disulfide formaGlutathione dynamic aspects of protein mixed disulfide formation in "glutathione" chemical, biochemical and medict

42 Bellomo G, Thor H, Eklow L, Nicotera P, Orrenius S. Oxidative stress: mechanisms of cytotoxicity. Chemica Scripta 1987;27A:117-21.

43 Curello S, Ceconi C, Cargnoni A, Madici D, Ferrari R. Oxidative stress during myocardial ischaemia and reperfusion: experimental and clinical evidence. $\mathcal{F}$ Appl Cardiol 1986;1:311-27.

44 Julia PL, Buckberg GD, Acar C, Partington MT, Sherman MP. Studies of controlled reperfusion after ischaemia: XXI reperfusate composition superiority of blood cardioplegia over crystalloid cardioplegia in limiting reperfusion damage. Importance of endogenous oxygen free radica scavengers in red blood cells. $\mathcal{F}$ Thorac Cardiovasc Surg 1991;101:303-13.

45 Kramer JH, Arroyo CM, Dickens BF, Weglicki WB. Spintrapping evidence that graded myocardial ischaemia alters post-ischemic superoxide production. Free Radic Biol Med 1987;3:153-9.

46 Yau TM, Ikonomidis JS, Weisel RD, Mickle DAG, Ivanov JRN, Mohabeer MK, et al. Ventricular function after normothermic versus hypothermic cardioplegia. $\mathcal{F}$ Thorac Cardiovascular Surg 1993;105:833-44.

47 Ki-Bong K, Hyoung HC, Myung SK, Joon Ryang R. Changes in the antioxidative defensive system during open heart operations in humans. Ann Thorac Surg 1994; 58:170-5. 